\title{
Use of stented bovine pericardial valve for surgical mitral valve replacement in infants
}

Paul J. Chai, MD, ${ }^{\mathrm{a}}$ Isaac George, MD, ${ }^{\mathrm{a}}$ Tamim M. Nazif, MD, FACC, ${ }^{\mathrm{b}}$ David M. Kalfa, MD, PhD,

Susheel K. Kodali, MD, FACC, ${ }^{\mathrm{b}}$ Alejandro J. Torres, MD, ${ }^{\mathrm{c}}$ Julie A. Vincent, MD,

Martin B. Leon, MD, FACC, ${ }^{b}$ and Emile A. Bacha, MD, ${ }^{a}$ New York, NY

From the a Division of Cardiothoracic Surgery, New York-Presbyterian Hospital College of Physicians and Surgeons of Columbia University, New York, NY; the ${ }^{\mathrm{b}}$ Herbert and Sandi Feinberg Interventional Cardiology and Heart Valve Center at Columbia University Medical Center New York-Presbyterian Hospital, New York, NY; and the ${ }^{c}$ Division of Pediatric Cardiology, New York-Presbyterian Hospital College of Physicians and Surgeons of Columbia University, New York, NY.

Disclosures: M.B.L. is an unpaid member of the PARTNER Trial executive committee. J.A.V. is a proctor and consultant for Medtronic and investigator of Edwards Sapien for pulmonary position (COMPASSION trial). T.M.N. is a consultant for Edwards Lifesciences and Medtronic. Authors have nothing additional to disclose with regard to commercial support.

Received for publication May 22, 2015; revisions received Aug 19, 2015; accepted for publication Sept 4, 2015; available ahead of print Oct 13, 2015.

Address for reprints: Paul J. Chai, MD, Columbia University Medical Center, Morgan Stanley Children's Hospital of New York-Presbyterian, 3959 Broadway, CHN 275, New York, NY 10032 (E-mail: pjc2164@cumc. columbia.edu).

J Thorac Cardiovasc Surg 2016;151:e51-2

$0022-5223 / \$ 36.00$

Copyright (C) 2016 by The American Association for Thoracic Surgery

http://dx.doi.org/10.1016/j.jtcvs.2015.09.050

There are few options available when mitral valve replacement is necessary in infants and children. ${ }^{1-3}$ The Edwards Sapien 3 transcatheter heart valve (Edwards Lifesciences, Irvine, Calif) is a stented bovine pericardial heart valve that may have potential advantages relative to currently used valves such as the Melody valve (Medtronic, Minneapolis, Minn) for the treatment of mitral valve disease in infants and small children. We present the first cases of successful mitral valve replacement with the 20$\mathrm{mm}$ Sapien 3 valve in 2 infants $(4.5 \mathrm{~kg}$ and $5 \mathrm{~kg})$. Both procedures were performed under an emergency use exemption in accordance with the US Food and Drug Administration and local institutional review board regulations.

\section{CLINICAL SUMMARY}

\section{Patient 1}

The first patient was a 9-month old girl $(5 \mathrm{~kg})$ with severe mitral valve stenosis, history of left congenital diaphragmatic hernia (status post repair) and geleophysic dysplasia. She was seen with rapid progression of severe mitral stenosis and a 2-week history of worsening respiratory distress. Mean gradients across the mitral valve increased from $8 \mathrm{~mm} \mathrm{Hg}$ to $42 \mathrm{~mm} \mathrm{Hg}$ during the course of 5 months.

After an initial attempt at valve repair was unsuccessful, the valve leaflets and subvalvular apparatus were excised. The valve annulus was estimated at $15 \mathrm{~mm}$. The valve was crimped directly onto a $16 \mathrm{~F}$ valvuloplasty balloon and placed through the mitral annulus. The valve was partially dilated to $12 \mathrm{~mm}$, and the valve was secured with 5-0 Prolene (Ethicon, Inc, Somerville, NJ) to the mitral annulus with the fabric "skirt" of the valve (Figure 1). The valve was then

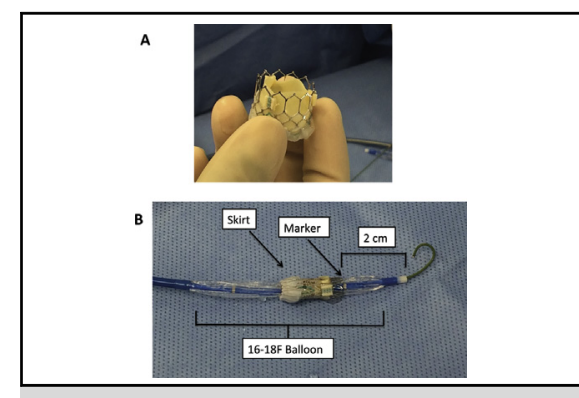

Edwards Sapien 3 valve before implantation (A) and after crimping to balloon catheter (B).

\section{Central Message}

The first in human use of an Edwards Sapien 3 transcatheter heart valve for surgical mitral valve replacement in infants is described.

See Editorial Commentary page e53.

expanded to its final target size of approximately $15 \mathrm{~mm}$ (Figure 2). Echocardiography showed excellent function of the mitral valve, with no left ventricular outflow tract (LVOT) obstruction and no mitral regurgitation or stenosis and with transmitral peak and mean gradients of 11 and $4 \mathrm{~mm} \mathrm{Hg}$, respectively. The patient was extubated on postoperative day (POD) 7 and discharged on postoperative day 14. At 3-month follow-up, the patient remained clinically well; however, echocardiography demonstrated an increase in the mean gradient across the mitral valve to 13 to $15 \mathrm{~mm} \mathrm{Hg}$ and also showed mild regurgitation. At 5-month follow-up, the mean gradient across the mitral valve had increased to $22 \mathrm{~mm} \mathrm{Hg}$, with the beginnings of respiratory symptoms. The patient was taken to the catheterization laboratory, where the mitral valve was successfully dilated with improvement in the mean mitral valve gradient to $13 \mathrm{~mm} \mathrm{Hg}$ and resolution of symptoms. Mitral valve regurgitation remained mild (unchanged) after dilation.

\section{Patient 2}

The second patient was a 4-month-old boy $(4.5 \mathrm{~kg})$ who had undergone a Ross procedure and mitral valve repair at 5 weeks of age for severe aortic stenosis and moderate mitral regurgitation. He was readmitted at 4 months of age with severe respiratory distress. Echocardiography showed marked left atrial dilatation, with abnormal, 

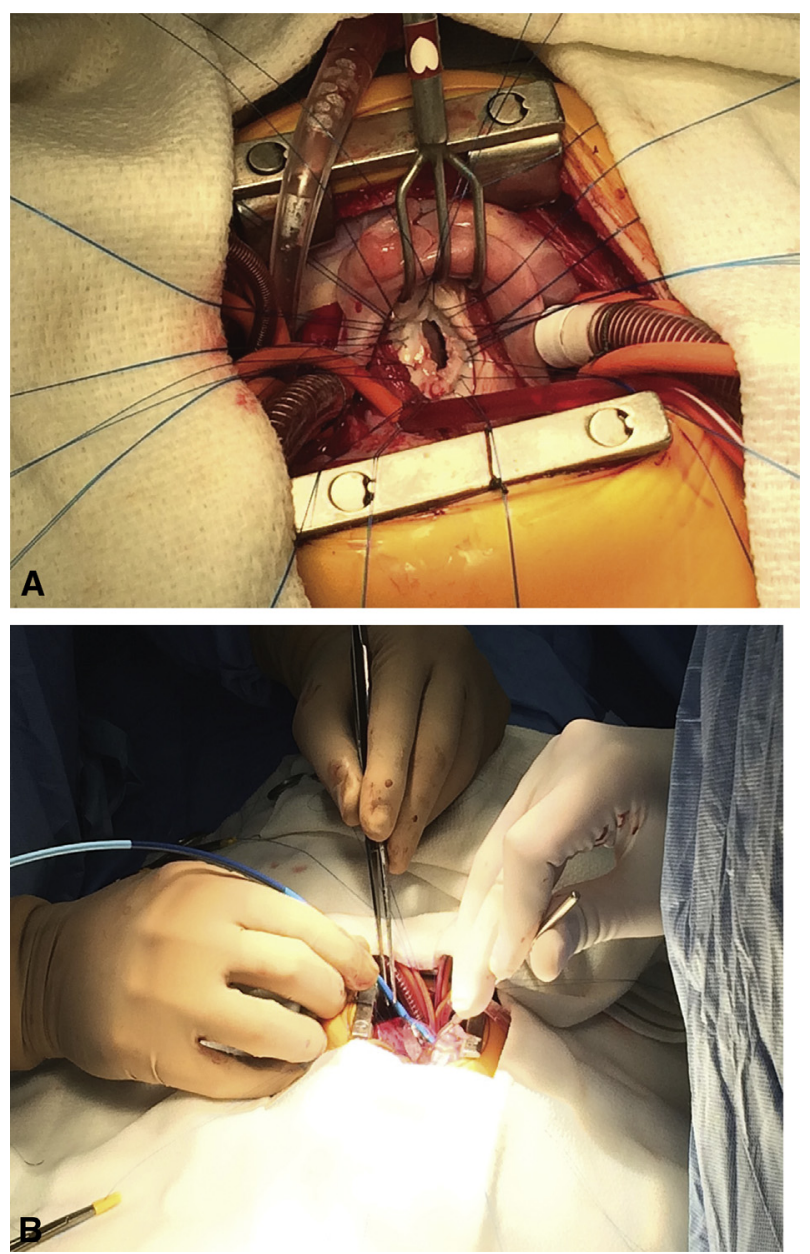

FIGURE 1. A, Sutures are placed around the mitral valve annulus on the atrial side. B, The valve is positioned through the mitral annulus before balloon expansion.

thickened valve leaflets and severe mitral regurgitation. The Sapien 3 valve was implanted as in patient 1 . The final expanded diameter was approximately $18 \mathrm{~mm}$. At discharge, the mean gradient across the mitral valve was $4 \mathrm{~mm} \mathrm{Hg}$. A small paravalvular leak was noted, with no mitral regurgitation. At 3-month follow-up, echocardiography showed a mild increase in the mean gradient across the mitral valve to $13 \mathrm{~mm} \mathrm{Hg}$. There was no significant LVOT obstruction, with a peak gradient of $12 \mathrm{~mm} \mathrm{Hg}$. Echocardiography at 5-month follow-up was unchanged. The patient has remained clinically well.

\section{DISCUSSION}

The Edwards Sapien 3 valve may have potential advantages relative to the Melody valve in the mitral position. The leaflets of the Sapien valve are attached primarily to the proximal aspect of the stent frame. This leaves the distal outflow aspect of the stent uncovered and allows blood to flow through the stent cells, potentially mitigating LVOT obstruction. The Edwards Sapien 3 valve is also relatively

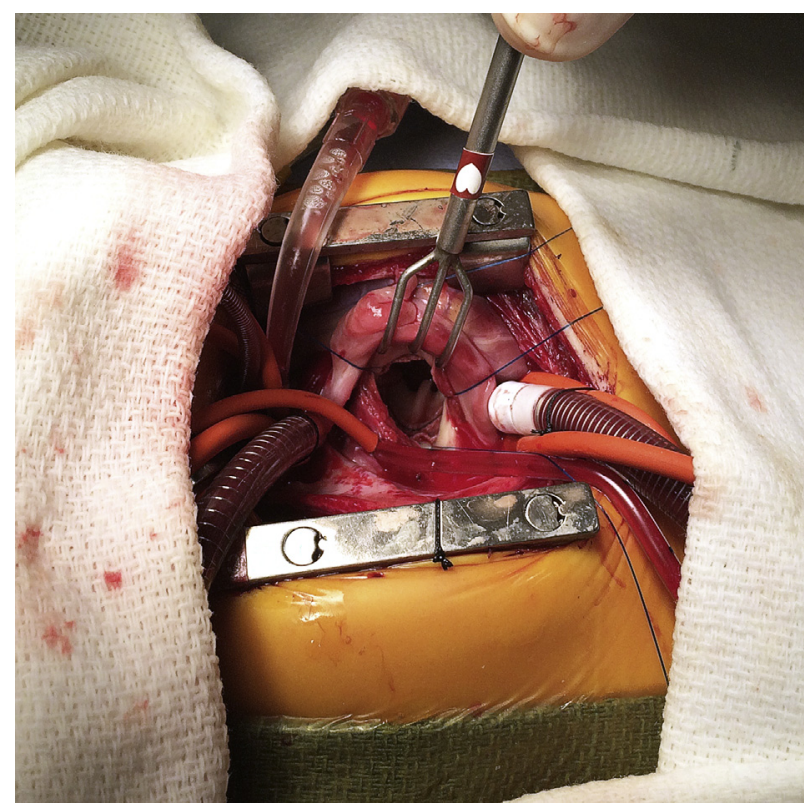

FIGURE 2. Sapien valve after implantation.

short (relative to the Melody valve), which further reduces the risk of LVOT obstruction as well as of pulmonary vein obstruction. The presence of a fabric "skirt" around the base of the valve also helps to facilitate securement with sutures and helps to avoid paravalvular leaks.

Both implanted valves in our series exhibited increased transmitral gradients at 3-month follow-up. This was thought to be due to the significantly improved hemodynamics and cardiac output of the patients seen after mitral valve replacement. A "pinwheeling" effect that can occur as a result of incomplete expansion of the valves may also have contributed to the increased gradients. Successful interval balloon dilation was accomplished in the catheterization laboratory in the first case.

\section{CONCLUSIONS}

In conclusion, we present the first use of the Edwards Sapien 3 valve in the mitral position in human infants. This report demonstrates the feasibility and early safety of this valve for use in native mitral valve replacement in children. Two procedures were performed safely without complications and provided excellent hemodynamic results in the short term. Further investigation is planned.

\section{References}

1. Adatia I, Moore PM, Jonas RA, Colan SD, Lock JE, Keane JF. Clinical course and hemodynamic observations after supraannular mitral valve replacement in infants and children. J Am Coll Cardiol. 1997;29:1089-94.

2. Quiñonez LG, Breitbart R, Tworetsky W, Lock JE, Marshall AC, Emani SM. Stented bovine jugular vein graft (Melody valve) for surgical mitral valve replacement in infants and children. J Thorac Cardiovasc Surg. 2014;148:1443-9.

3. Selamet Tierney ES, Pigula FA, Berul CI, Lock JE, del Nido PJ, McElhinney DB Mitral valve replacement in infants and children 5 years of age or younger: evolution in practice and outcome over three decades with a focus on supra-annular prosthesis implantation. J Thorac Cardiovasc Surg. 2008;136:954-61. 961.e1-3. 